\title{
NORMAS DE PROTECCIÓN DEL INVERSOR EN PLATAFORMAS DE FINANCIACIÓN PARTICIPATIVA PARA EMPRESAS EN EL REGLAMENTO 2020/1503
}

\author{
Alicia Agüero Ortiz \\ Profesora Ayudante Doctora de Derecho Civil \\ Universidad Autónoma de Madrid
}

Title: Investor protection regime on crowdfunding platforms for business under Regulation 2020/1503

Resumen: A lo largo de este trabajo analizaremos el régimen de protección al inversor en plataformas de financiación participativa para empresas previsto en el Reglamento (UE) 2020/1503 del Parlamento Europeo y del Consejo, de 7 de octubre de 2020, relativo a los proveedores europeos de servicios de financiación participativa para empresas, y por el que se modifican el Reglamento (UE) 2017/1129 y la Directiva (UE) 2019/1937.

Palabras clave: financiación participativa, Reglamento (UE) 2020/1503, inversor, MiFID II, idoneidad, ficha de datos fundamentales de la inversión.

Abstract: Throughout this paper we will analyze the investor protection regime on crowdfunding platforms for business introduced by Regulation (EU) 2020/1503 of the European Parliament and of the Council of 7 October 2020 on European crowdfunding service providers for business, and amending Regulation (EU) 2017/1129 and Directive (EU) 2019/1937.

Key words: Crowdfunding, Regulation 2020/1503, investor, MiFID II, suitability, key investment information sheet.

SUMARIO: 1. Principales normas de conducta y especial referencia al servicio de gestión de carteras de préstamos. 2. Clasificación de inversores: experimentados y no experimentados. 3. Obligaciones informativas. 4. Ficha de datos fundamentales de la inversión. 4.1. Requisitos formales. 4.2. Contenido de la ficha de datos fundamentales de la inversión. 4.3. Modificaciones, inexactitudes y responsabilidad por el contenido de la ficha de datos fundamentales de la inversión. 5 . Ficha de datos fundamentales de la inversión a nivel de plataforma. 6. Prueba inicial de conocimientos y simulación de la capacidad de soportar pérdidas. 7. Advertencia específica para inversiones "elevadas" de inversores no experimentados. 8. Información pública sobre la tasa de impago. 9. Período de reflexión de inversores no expertos. 10.Tablón de anuncios. 11. Conclusiones. 12. Bibliografía. 


\section{Principales normas de conducta y especial referencia al servicio de gestión de carteras de préstamos}

Los proveedores de servicios de financiación participativa deberán actuar de manera honesta, equitativa y profesional atendiendo al mejor interés de sus clientes (art. 3.2. Reglamento 2020/1503). Además, no pagarán ni aceptarán ningún tipo de remuneración, descuento o rendimiento no pecuniario por orientar las órdenes de los inversores hacia una determinada oferta realizada en sus plataformas, o plataformas de terceros (art. 3.3. Reglamento 2020/1503).

Por su parte, a diferencia de lo que sucede en MiFID II, en el Reglamento 2020/1503 no existe servicio de asesoramiento a favor de los clientes. En este sentido, el art. 3.4 Reglamento 2020/1503 dispone que "los proveedores de servicios de financiación participativa podrán proponer a los inversores individualmente proyectos de financiación participativa específicos que correspondan a uno o varios parámetros específicos o indicadores de riesgo elegidos por el inversor. Cuando el inversor desee realizar una inversión en los proyectos de financiación participativa propuestos, tendrá que estudiar todas las ofertas de financiación participativa y tomar de forma expresa una decisión de inversión respecto de cada una de ellas". Como puede observarse, la decisión de inversión recae de exclusivamente sobre el inversor experimentado o no-, ya que la propuesta no constituye "recomendación", esto es, no comporta un juicio de valor relativo a la idoneidad de la inversión respecto a los objetivos y situación financiera del cliente, sino solo de cabida en los parámetros señalados por inversor. Tampoco debe considerarse asesoramiento la existencia de herramientas de filtrado en la propia plataforma (considerando 21 Reglamento 2020/1503).

Por el contrario, sí existe posibilidad de ofrecer un servicio de gestión individualizada de carteras de préstamos, en contraposición con la prohibición contenida en el art. 52.2.a) LFFE ${ }^{1}$. En estos casos, el proveedor deberá actuar respetando los parámetros comunicados por los inversores y habrá de tomar las medidas necesarias para ofrecer el mejor resultado posible a dichos inversores. Asimismo, deberá comunicar a los inversores el proceso de toma de decisiones para la ejecución del mandato discrecional que han recibido (art. 3.4.II Reglamento 2020/1503).

En concreto, el inversor otorgará un mandato que especificará los parámetros de prestación del servicio y que incluirá al menos dos de los criterios siguientes, que todos los préstamos de la cartera deberán cumplir: (i) el tipo de interés mínimo y máximo que se pagará en el marco de cada préstamo facilitado al inversor; (ii) la fecha de vencimiento mínima y máxima de los préstamos facilitados al inversor; (iii) la gama y la distribución de cualquier categoría de riesgo aplicable a los préstamos; y/o (iv) en caso de que se ofrezca un tipo objetivo anual de rentabilidad de la inversión, la probabilidad de que los préstamos seleccionados permitan al inversor alcanzar el tipo objetivo con un grado de certeza razonable (art. 6.1 Reglamento 2020/1503).

\footnotetext{
${ }^{1}$ Al respecto, CASASOLA DÍAZ, J. Ma.: "Las plataformas de financiación participativa: concepto, régimen y referencia especial a la protección del inversor consumidor", eXtoikos, no. 19, 2017, p. 14.
} 
Para ejecutar el mandato, el proveedor deberá evaluar (i) el riesgo de crédito de los distintos proyectos de financiación participativa seleccionados para la cartera del inversor; (ii) el riesgo de crédito al nivel de la cartera del inversor; y (iii) el riesgo de crédito de los promotores de proyectos seleccionados para la cartera del inversor, verificando la probabilidad de que los promotores de proyectos cumplan sus obligaciones derivadas del préstamo (art. 6.2 Reglamento 2020/1503). En adición, deberá entregar al inversor una descripción del método utilizado en las evaluaciones mencionadas; así como información permanente y a petición del inversor sobre la configuración y evolución de su cartera e inversiones (art. 6.4 Reglamento 2020/1503).

\section{Clasificación de inversores: experimentados y no experimentados}

"Un inversor experimentado es un inversor consciente de los riesgos asociados a la inversión en los mercados de capitales y con recursos suficientes para asumir dichos riesgos sin exponerse a consecuencias financieras excesivas" (Anexo II, Sección I Reglamento 2020/1503). El concepto clasificatorio difiere, pues, de MiFID II (inversores profesionales e inversores minoristas) y del previsto en la Ley 5/2015, de 27 de abril, de fomento de la financiación empresarial (en adelante, "LFFE") que distinguía entre inversores acreditados y no acreditados.

En concreto, podrán ser considerados inversores experimentados las personas jurídicas que cumplan al menos uno de los siguientes criterios: (i) que cuenten con recursos propios de, al menos, $100000 \epsilon_{;}$(ii) que su volumen de negocios neto sea de, al menos, $2000000 €$; o que (iii) su balance sea de, al menos, $1000000 €$ (requisitos menos exigentes que los requeridos para ser considerado inversor profesional ope legis bajo la LFFE (art. 81) y MiFID II, sin perjuicio de que estos últimos merecerán su calificación como inversores experimentados, también ope legis, en el Reglamento 2020/1503 como se explicará más abajo)².

\begin{tabular}{|c|c|c|c|}
\hline & Reglamento 2020/1503 & LFFE & MiFID II \\
\hline $\begin{array}{c}\text { Activo } \\
\begin{array}{c}\text { Cifra anual de } \\
\text { negocio }\end{array}\end{array}$ & $1000000 €$ & $1000000 €$ & $20000000 €$ \\
\hline $\begin{array}{c}\text { Recursos propios } \\
\text { Recul| }\end{array}$ & $2000000 €$ & $2000000 €$ & $40000000 €$ \\
\hline
\end{tabular}

Asimismo, podrán ser considerados inversores experimentados las personas físicas que cumplan al menos dos de los siguientes criterios: (i) que sus ingresos brutos personales sean de, al menos, $60000 €$ por ejercicio fiscal, o que disponga de una cartera de instrumentos financieros superior a $100000 €$ (en la que se incluyen

\footnotetext{
${ }^{2}$ Respecto a la clasificación de inversores en la LFFE y las consecuencias anudadas a cada categoría, véase FLORES SEGURA, M.: "La tipología de inversores en las operaciones de financiación participativa o «crowdfunding»", Revista de Derecho Bancario y Bursátil, nº 150, 2018.
} 
depósitos de efectivo y activos financieros); (ii) que trabaje o haya trabajado en el sector financiero durante un año, por lo menos, en un puesto que requiera tener conocimiento de las operaciones o servicios previstos, o que haya ocupado un puesto ejecutivo durante, al menos, un año, en una persona jurídica que cumpliera los requisitos para ser considerada inversor experimentado; y/o (iii) que hubiera realizado operaciones de "volumen significativo" en los mercados de capitales con una frecuencia media de diez por trimestre durante los cuatro trimestres anteriores (de nuevo, requisitos menos exigentes que los previstos en MiFID II) ${ }^{3}$.

\begin{tabular}{|c|c|c|c|}
\hline & $\begin{array}{c}\text { Reglamento } \\
2020 / 1503\end{array}$ & LFFE $^{4}$ & MiFID II \\
\hline & Personas físicas & $\begin{array}{l}\text { Personas } \\
\text { físicas }\end{array}$ & Personas físicas y jurídicas \\
\hline $\begin{array}{c}\text { Ingresos } \\
\text { brutos }\end{array}$ & $60000 €$ & $50000 €$ & $\mathrm{n} / \mathrm{a}$ \\
\hline $\begin{array}{c}\text { Cartera de } \\
\text { instrumentos }\end{array}$ & $100000 €$ & $100000 €$ & $500000 €$ \\
\hline \multirow[b]{2}{*}{$\begin{array}{l}\text { Experiencia } \\
\text { profesional }\end{array}$} & $\begin{array}{l}\text { Cargo profesional en } \\
\text { el sector financiero } \\
\text { durante } 1 \text { año }\end{array}$ & & \multirow[b]{2}{*}{$\begin{array}{l}\text { Cargo profesional en el } \\
\text { sector financiero durante } \\
1 \text { año }\end{array}$} \\
\hline & $\begin{array}{c}\text { Puesto ejecutivo } \\
\text { durante } 1 \text { año en una } \\
\text { empresa con } \\
\text { requisitos de inversor } \\
\text { experimentado }\end{array}$ & $\mathrm{n} / \mathrm{a}$ & \\
\hline $\begin{array}{l}\text { Experiencia } \\
\text { inversora }\end{array}$ & $\begin{array}{c}10 \text { operaciones de } \\
\text { volumen significativo } \\
\text { durante los } 4 \\
\text { trimestres anteriores }\end{array}$ & $\mathrm{n} / \mathrm{a}$ & $\begin{array}{c}10 \text { operaciones de } \\
\text { volumen significativo } \\
\text { durante los } 4 \text { trimestres } \\
\text { anteriores }\end{array}$ \\
\hline
\end{tabular}

Ahora bien, a diferencia de lo que sucede en MiFID II respecto a los inversores profesionales, el cumplimiento de estos requisitos no comporta su clasificación

\footnotetext{
${ }^{3}$ En contraste con MiFID II, recordemos que podrían solicitar su tratamiento como inversores profesionales los inversores minoristas que cumplieran con dos de los siguientes requisitos: (i) que hubieran realizado en el mercado de valores de que se trate operaciones de volumen significativo con una frecuencia media de 10 por trimestre durante los cuatro trimestres anteriores; (ii) que el valor de la cartera de instrumentos financieros del cliente, formada por depósitos de efectivo e instrumentos

financieros, fuera superior a $500000 €$; y/o (iii) que ocupase o hubiera ocupado por lo menos durante un año un cargo profesional en el sector financiero que requiera conocimientos sobre las operaciones o los servicios previstos.

${ }^{4}$ Como explica CUENA CASAS, en la LFFE "un inversor puede solicitar su condición de acreditado y ello depende de su capacidad económica y no de su grado de conocimiento, experiencia y cualificación necesarios para valorar sus riesgos. Para que se le conceda la condición de inversor acreditado tiene que tener una capacidad económica "potente" que demuestre su capacidad para soportar pérdidas". CUENA CASAS, M.: "La protección del inversor en el crowdfunding lucrativo", en CUENA CASAS, M. (Dir.) Aspectos legales de la financiación en masa o crowdfunding, Tirant lo Blanch, 2020, p. 480.
} 
automática como inversores experimentados. Por el contrario, casi todos los inversores partirán de su clasificación como inversores no experimentados y solo si solicitaran su tratamiento como inversores experimentados ${ }^{5}$, y se verificara el cumplimiento de los requisitos expuestos, podrán ser tratados como tales (Anexo II, Sección II Reglamento 2020/1503).

En concreto, los proveedores de servicios de financiación participativa deberán poner a disposición de sus inversores una plantilla que puedan utilizar para solicitar el tratamiento como inversores experimentados, en la que especificarán los requisitos para ser tratados como tales, así como una advertencia clara en la que se señale la protección que perderá como consecuencia de ser calificado como inversor experimentado. En esta solicitud de tratamiento como inversor experimentado, el inversor deberá aportar: (i) un certificado que especifique cuáles de los criterios que cumple para ser tratado como inversor experimentado; (ii) una declaración de ser consciente de las consecuencias de perder la protección vinculada a la categoría de inversor no experimentado; y (iii) una declaración responsabilidad de la veracidad de la información facilitada en la solicitud.

Una vez recibida la solicitud de tratamiento como inversor experimentado, el proveedor aprobará tal solicitud, salvo que tenga dudas razonables sobre la veracidad de la información aportada. Aprobada la solicitud, notificará expresamente al inversor el cambio de clasificación, que tendrá una duración de dos años. Expirados los dos años de validez de la clasificación como inversor experimentado, el inversor que quisiera mantener este tratamiento, deberá remitir una nueva solicitud ${ }^{6}$.

Si durante el periodo de dos años de tratamiento como inversor experimentado acaecieran circunstancias que comportase que el inversor ya no cumpliera con los requisitos para ser tratado como tal, será obligación del propio inversor comunicar al proveedor dicho cambio de circunstancias. De esta suerte, cuando el proveedor de servicios de financiación participativa tenga conocimiento de que el inversor ya no cumple las condiciones iniciales que permitieron a este recibir tratamiento de inversor experimentado, deberá informar al inversor de que se le tratará como inversor no experimentado.

La única excepción a la regla, según la cual todos los inversores parten de su clasificación de inversores no experimentados y solo tras su solicitud podrán ser tratados como inversores experimentados, la encontramos en la Sección III del

\footnotetext{
${ }^{5}$ Excepción hecha a los inversores que ostentasen la condición de inversores profesionales de conformidad con MiFID II, vid. infra. Igualmente sucedía en el art. 81.2.c) LFFE en relación con las personas físicas, que solo podrían ser considerados inversores acreditados si cumplieran los requisitos previstos y solicitaran tal tratamiento.

${ }^{6}$ Como señala TAPIA HERMIDA, A. J. la clasificación de estos inversores como profesionales se realiza en un proceso integrado por dos fases: (i) la del cumplimiento de los requisitos; y (ii) la de solicitud. "La nueva regulación europea del crowfunding (4): El Reglamento (UE) 2020/1503, de 7 de octubre de 2020, sobre los proveedores europeos de servicios de financiación participativa para empresas", disponible en: http://ajtapia.com/2020/10/la-nueva-regulacion-europea-del-crowfunding-4-el-reglamento-ue-20201503-de-7-de-octubre-de-2020-sobre-los-proveedores-europeos-de-servicios-de-financiacionparticipativa-para-empresas/ (última consulta: 5/12/2020).
} 
Anexo II Reglamento 2020/1503. En particular, serán considerados ope legis inversores experimentados los inversores que, de conformidad con MiFID II (Anexo II, Sección I, apartados 1-4), ostenten la condición de profesionales ope legis, a saber:

a) Las entidades que deben ser autorizadas o reguladas para operar en los mercados financiero: entidades de crédito, empresas de servicios de inversión; compañías de seguros; instituciones de inversión colectiva y sus sociedades de gestión; los fondos de pensiones y sus sociedades de gestión; operadores en materias primas y en derivados de materias primas; etc.;

b) Las grandes empresas que, a escala individual, cumplan dos de los siguientes requisitos: (i) total del balance: $20000000 €$; (ii) volumen de negocios neto: $40000000 €$; y/o (iii) fondos propios: $2000000 €$;

c) Los Gobiernos nacionales y regionales, incluidos los organismos públicos que gestionan la deuda pública a escala nacional y regional, bancos centrales, organismos internacionales y supranacionales como el Banco Mundial, el FMI, el BCE, el BEI y otras organizaciones internacionales similares; y

d) Otros inversores institucionales cuya actividad como empresa es invertir en instrumentos financieros, incluidas las entidades dedicadas a la titularización de activos u otras transacciones de financiación.

Por último, debemos destacar que el Reglamento 2020/1503 no prevé una clasificación como inversor experimentado por razón de los servicios contratados, como contempla el art. 81.3 LFFE. Dicho precepto estipula que "también tendrán la consideración de inversor acreditado las personas físicas o jurídicas que acrediten la contratación del servicio de asesoramiento financiero sobre los instrumentos de financiación de la plataforma por parte de una empresa de servicios de inversión autorizada"7. Por tanto, si el inversor no satisficiera los requisitos expuestos para ser tratado como inversor experimentado, conservará su condición de inversor no experimentado, incluso cuando una empresa de servicios de inversión le prestara un servicio de asesoramiento sobre instrumentos de financiación participativa.

\section{Obligaciones informativas}

Toda la información que se facilite a los inversores por los proveedores de servicios de financiación participativa, incluidas las comunicaciones publicitarias, deberá ser imparcial, clara y no engañosa (art. 19.1 Reglamento 2020/1503).

\footnotetext{
7 Como señala CAMACHO CLAVIJO, S.: "para ser "acreditado" no bastará con probar la contratación del servicio de asesoramiento sino que, en virtud de la TRLMV (art 209.3, 4 y 6 ) el inversor tiene que superar un previo test de idoneidad realizado por la entidad de servicios de inversión para comprobar si la propuesta de inversión es adecuada a los conocimientos, experiencia, situación financiera y objetivos del inversor". En "El crowdfunding: régimen jurídico de la financiación participativa en la Ley 5/2015 de fomento de la financiación empresarial", Revista CESCO de Derecho de Consumo, no 17/2016, p. 105. Igualmente, ZUNZUNEGUI, F.: "Régimen jurídico de las plataformas de financiación participativa (crowdfunding)", Revista de Derecho del Mercado Financiero, junio 2015, p. 25.
} 
Los proveedores de servicios de financiación participativa deberá informar a sus clientes, al menos antes de proceder a la operación de financiación participativa, sobre (i) los costes, riesgos financieros y cargas relacionados con los servicios o inversiones de financiación participativa; (ii) los criterios de selección de los proyectos de financiación participativa; y (iii) sobre la naturaleza y los riesgos asociados a sus servicios de financiación participativa (art. 19.1 y 4 Reglamento 2020/1503). Esta información, además, deberá ser puesta a disposición de todos los clientes en una sección fácilmente accesible del sitio web de la plataforma de financiación participativa (art. 19.5 Reglamento 2020/1503).

Asimismo, los proveedores de servicios de financiación participativa informarán a sus clientes de que sus servicios de financiación participativa no están cubiertos por el sistema de garantía de depósitos (Directiva 2014/49/UE), y de que los valores negociables o los instrumentos admitidos para la financiación participativa adquiridos a través de su plataforma de financiación participativa tampoco están cubiertos por el sistema de indemnización de los inversores (Directiva 97/9/CE), (art. 19.2 Reglamento 2020/1503). En principio, esta obligación de información sobre la ausencia de cobertura por el sistema de garantía de depósitos ni por el sistema de indemnización de los inversores solo debe ser puesta a disposición de los clientes en el sitio web de la plataforma (art. 19.5 Reglamento 2020/1503), sin que se exija su comunicación con carácter previo a la conclusión de la operación de financiación participativa (cfr. art. 19.4 Reglamento 2020/1503).

Si el inversor no fuera experimentado, se le informará además del período de reflexión que le asiste, de conformidad con el art. 22 Reglamento 2020/1503. Siempre que se haga una oferta de financiación participativa, el proveedor de servicios de financiación participativa facilitará dicha información en un lugar destacado del soporte, también en las aplicaciones móviles y páginas web en que se haga dicha oferta (art. 19.3 Reglamento 2020/1503).

Por último, si los proveedores de servicios de financiación participativa sometieran a calificación crediticia los proyectos de financiación participativa o sugirieran una determinación de precios de riesgos de las ofertas de financiación participativa de su plataforma, deberán ofrecer a los clientes una descripción del método utilizado para calcular las calificaciones o la determinación del precio de los créditos. Si el cálculo se basara en cuentas que no hubieran sido auditadas, deberán hacerlo constar claramente en la descripción del método (art. 19.6 Reglamento 2020/1503). Esta información sobre el método de cálculo utilizado para determinar las calificaciones o precio de los créditos deberá ser puesta a disposición de todos los clientes en una sección fácilmente accesible del sitio web de la plataforma de financiación participativa (art. 19.5 Reglamento 2020/1503).

\section{Ficha de datos fundamentales de la inversión}

\subsection{Requisitos formales}

Los proveedores de servicios de financiación participativa facilitarán a los inversores potenciales (experimentados y no experimentados) una ficha de datos fundamentales de la inversión elaborada por el promotor del proyecto para cada oferta de 
financiación participativa ${ }^{8}$. Esta ficha se redactará como mínimo en una de las lenguas oficiales del Estado miembro cuyas autoridades competentes hayan concedido la autorización o en otra lengua aceptada por dichas autoridades. Además, si el proveedor publicitara la oferta mediante una comunicación comercial en otro Estado miembro, la ficha deberá estar disponible en al menos una de las lenguas oficiales de dicho Estado miembro o en una lengua aceptada por las autoridades competentes de ese Estado miembro (art. 23.2 y 3 Reglamento 2020/1503). Asimismo, se reconoce el derecho de todo inversor potencial a solicitar a los proveedores la traducción de la ficha a la lengua de elección del inversor de suerte que, si el proveedor no proporcionase la traducción, deberá aconsejar claramente a los inversores que se abstengan de realizar la inversión (art. 23.13 Reglamento 2020/1503). A estos efectos, no se podrá prohibir a los proveedores la traducción de la ficha, que deberá reflejar con exactitud su contenido original (art. 23.4 Reglamento 2020/1503).

La ficha de datos fundamentales de la inversión deberá ser imparcial, clara y no engañosa y no deberá notas a pie de página, salvo las que incluyan referencias a la normativa aplicable, "incluidas las citas que convengan". Se presentará en soporte duradero, independiente, que se distinga claramente de las comunicaciones publicitarias. Su versión impresa no podrá exceder de seis caras de papel en tamaño A4. En el caso de instrumentos admitidos a efectos de financiación participativa, si la parte $F$ del anexo I (derechos del inversor) excediera de un formato en papel de tamaño A4 por una sola cara en formato impreso, el resto se incluirá como anexo adjunto a la ficha (art. 23.7 Reglamento 2020/1503).

\subsection{Contenido de la ficha de datos fundamentales de la inversión}

Por lo que respecta al contenido de la ficha de datos fundamentales de la inversión, esta deberá incluir, además de la información contenida en el Anexo I:

(i) Una cláusula de exención de responsabilidad, que figurará bajo el título de la ficha, con la siguiente redacción: "La presente oferta de financiación participativa no ha sido verificada ni aprobada por las autoridades competentes ni por la Autoridad Europea de Valores y Mercados (AEVM).

La idoneidad de su experiencia y conocimientos no se ha evaluado necesariamente antes de que se le concediera acceso a esta inversión. Al realizar esta inversión, usted asume plenamente el riesgo que comporta, incluido el de pérdida parcial o total del dinero invertido"; así como

(ii) Una advertencia de riesgo del siguiente tenor: "Invertir en este proyecto de financiación participativa entraña riesgos, incluido el de pérdida parcial o total del dinero invertido. Su inversión no está cubierta por los sistemas de garantía de depósitos establecidos de conformidad con la Directiva

\footnotetext{
8 Se considerará que los proveedores de servicios de financiación participativa y los promotores de proyectos cumplen la obligación de elaborar un documento de datos fundamentales de conformidad con el Reglamento (UE) n.o 1286/2014 del Parlamento Europeo y del Consejo (PRIIPs) cuando entreguen la ficha de datos fundamentales de la inversión del Reglamento 2020/1503 (art. 23.15).
} 
2014/49/UE del Parlamento Europeo y del Consejo (*1). Su inversión no está cubierta por los sistemas de indemnización de los inversores establecidos de conformidad con la Directiva 97/9/CE del Parlamento Europeo y del Consejo (*2).

Es posible que no obtenga rendimiento alguno de su inversión.

No se trata de un producto de ahorro y recomendamos no invertir más del $10 \%$ de su patrimonio neto en proyectos de financiación participativa.

Es posible que no pueda vender los instrumentos de inversión cuando lo desee. Aun cuando pueda venderlos, podría sufrir pérdidas.

(*1) Directiva 2014/49/UE del Parlamento Europeo y del Consejo, de 16 de abril de 2014, relativa a los sistemas de garantía de depósitos (DO L 173 de 12.6.2014, p. 149).

(*2) Directiva 97/9/CE del Parlamento Europeo y del Consejo, de 3 de marzo de 1997, relativa a los sistemas de indemnización de los inversores (DO L 84 de 26.3.1997, p. 22)".

A este respecto, señala el considerando 45 que "los proveedores de servicios de financiación participativa solo deben aceptar inversiones realizadas por inversores no experimentados que hayan reconocido expresamente haber recibido y comprendido las advertencias".

Por su parte, de conformidad con el Anexo I, la ficha estará dividida en ocho partes, como sigue:

Parte A: Información sobre el promotor del proyecto y el proyecto de financiación participativa

a) Identidad, forma jurídica, titularidad, puestos directivos y datos de contacto.

b) Todas las personas físicas o jurídicas responsables de la información facilitada en la ficha de datos fundamentales de la inversión. Si se trata de personas físicas, incluidos los miembros de los órganos de administración, de gestión o de supervisión del promotor del proyecto, indicar el nombre y el cargo de la persona física; si se trata de personas jurídicas, indicar la denominación y el domicilio social.

c) La siguiente declaración de responsabilidad:

d) «El promotor del proyecto declara que, hasta donde alcanza su conocimiento, no se ha omitido ningún dato y la información no es sustancialmente engañosa ni inexacta. El promotor del proyecto es el responsable de la elaboración de esta ficha de datos fundamentales de la inversión.».

e) Actividades principales del promotor del proyecto, productos o servicios ofrecidos por el promotor del proyecto. 
f) Un hipervínculo a los estados financieros más recientes del promotor del proyecto, si se dispone de ellos.

g) Principales cifras y coeficientes financieros anuales del promotor del proyecto de los tres últimos años, si se dispone de ellos.

h) Descripción del proyecto de financiación participativa, incluidas su finalidad y características principales.

Parte B: Principales características del proceso de financiación participativa y, en su caso, condiciones para captar capital o tomar prestados fondos

a) Importe mínimo de capital que se ha de captar o de fondos que se han de tomar en préstamo para cada oferta de financiación participativa y número de ofertas completadas por el promotor del proyecto o el proveedor de servicios de financiación participativa para el proyecto de que se trate.

b) Plazo para alcanzar el objetivo del capital que se ha de captar o de fondos que se han de tomar en préstamo.

c) Información sobre las consecuencias si no se alcanza dentro del plazo el objetivo de captación capital o de fondos tomados en préstamo.

d) Importe máximo de la oferta, si difiere del importe mínimo de capital o de fondos que se menciona en la letra a).

e) Importe de los recursos propios comprometidos por el promotor del proyecto en el proyecto de financiación participativa.

f) Modificaciones de la composición del capital o de los préstamos del promotor del proyecto relacionados con la oferta de financiación participativa.

g) Existencia y condiciones de un período de reflexión precontractual para inversores no experimentados.

Parte C: Factores de riesgo

Exposición de los principales riesgos asociados con la financiación del proyecto de financiación participativa, el sector, el proyecto, el promotor del proyecto, los valores negociables y los instrumentos admitidos para la financiación participativa o los préstamos, incluidos, en su caso, los riesgos geográficos.

Parte D: Información relativa a la oferta de valores negociables y a los instrumentos admitidos para la financiación participativa

a) Importe total y tipo de valores negociables e instrumentos admitidos para la financiación participativa que se van a ofrecer.

b) Precio de suscripción.

c) Si se acepta la sobredemanda de suscripciones y cómo se asigna.

d) Condiciones de suscripción y pago. 
e) Custodia y entrega a los inversores de los valores negociables y los instrumentos admitidos para la financiación participativa.

f) Cuando la inversión se garantice con un aval o una garantía real: (i) precisar si el avalista o el proveedor de la garantía real es una persona jurídica; (ii) precisar la identidad, la forma jurídica y los datos de contacto del avalista o del proveedor de la garantía real; (iii) ofrecer información sobre la naturaleza y las condiciones del aval o de la garantía real.

g) En su caso, compromiso firme de recompra de los valores negociables o los instrumentos admitidos para la financiación participativa, así como el plazo para dicha recompra.

h) Para los instrumentos distintos de acciones o participaciones, el tipo de interés nominal, la fecha de devengo de los intereses, las fechas de pago de intereses, la fecha de vencimiento y el rendimiento aplicable.

Parte E: Información sobre la entidad instrumental

a) Si existe una entidad instrumental interpuesta entre el promotor del proyecto y el inversor.

b) Datos de contacto de la entidad instrumental.

Parte F: Derechos del inversor

a) Derechos principales inherentes a los valores negociables o los instrumentos admitidos para la financiación participativa.

b) Restricciones a las que están sujetos los valores negociables o los instrumentos admitidos para la financiación participativa, en particular pactos parasociales u otros acuerdos que impidan su negociabilidad.

c) Descripción de cualquier restricción a la negociación de valores negociables o de los instrumentos admitidos para la financiación participativa.

d) Posibilidades del inversor de desprenderse de la inversión.

e) En relación con los instrumentos de renta variable, la distribución del capital y los derechos de voto antes y después de la ampliación de capital resultante de la oferta (suponiendo que se suscriban todos los valores negociables o los instrumentos admitidos para la financiación participativa).

Parte G: Comunicaciones relacionadas con préstamos

Cuando la oferta de financiación participativa incluya la facilitación de la concesión de préstamos, la ficha de datos fundamentales de la inversión contendrá la siguiente información, en lugar de la mencionada en las partes D, E y F del presente anexo:

a) la naturaleza, la duración y las condiciones del préstamo;

b) los tipos de interés aplicables o, en su caso, cualquier otra forma de compensación al inversor; 
c) las medidas de mitigación del riesgo, especialmente si existen avalistas o proveedores de garantía real u otro tipo de garantías;

d) calendario de reembolso del principal y de abono de los intereses;

e) cualquier incumplimiento de los contratos de crédito por parte del promotor del proyecto en los últimos cinco años;

f) la gestión del préstamo, especialmente en situaciones en las que el promotor del proyecto no cumple sus obligaciones.

Parte H: Tarifas, información y vías de recurso

a) Las tarifas cobradas al inversor y los costes soportados por este en relación con las inversiones, especialmente los costes administrativos que resulten de la venta de instrumentos admitidos para la financiación participativa.

b) Dónde y cómo obtener de forma gratuita información complementaria sobre el proyecto de financiación participativa, el promotor del proyecto y la entidad instrumental.

c) Cómo y a quién puede dirigir el inversor una reclamación sobre la inversión o sobre la conducta del promotor del proyecto o el proveedor de servicios de financiación participativa.

Parte I: Información sobre el servicio de gestión individualizada de carteras de préstamos que presten los proveedores de servicios de financiación participativa

a) Identidad, forma jurídica, titularidad, puestos directivos y datos de contacto del proveedor de servicios de financiación participativa.

b) El tipo de interés mínimo y máximo de los préstamos que puedan estar a disposición de las carteras individuales de los inversores.

c) La fecha de vencimiento mínima y máxima de los préstamos que puedan estar a disposición de las carteras individuales de los inversores.

d) Cuando se utilicen, la gama y la distribución de las categorías de riesgo a las que puedan pertenecer los préstamos, así como las tasas de impago y una media ponderada del tipo de interés por categoría de riesgo con un desglose adicional por año de concesión de los préstamos a través del proveedor de servicios de financiación participativa.

e) Los elementos principales de la metodología interna para evaluar el riesgo de crédito de los distintos proyectos de financiación participativa y para definir las categorías de riesgo.

f) En caso de que se ofrezca un tipo objetivo de rentabilidad de la inversión: un tipo objetivo anual y el intervalo de confianza de dicho tipo objetivo anual sobre el período de inversión, teniendo en cuenta los gastos y las tasas de impago. 
g) Los procedimientos, las metodologías internas y los criterios de selección de los proyectos de financiación participativa para la cartera individual de préstamos del inversor.

h) La cobertura y las condiciones de cualquier garantía del capital aplicable.

i) La gestión de los préstamos de la cartera, especialmente si un promotor del proyecto no cumple sus obligaciones.

j) Las estrategias de diversificación del riesgo.

k) Los gastos que debe pagar el promotor del proyecto o el inversor, especialmente cualquier deducción del interés que deba pagar el promotor del proyecto.

\subsection{Modificaciones, inexactitudes y responsabilidad por el contenido de la ficha de datos fundamentales de la inversión}

Los proveedores de servicios de financiación participativa deberán establecer y aplicar procedimientos adecuados para verificar la exhaustividad, exactitud y claridad de la información contenida en la ficha de datos fundamentales de la inversión (art. 23.11 Reglamento 2020/1503).

Si el proveedor detectase alguna omisión, error o inexactitud en la ficha de datos fundamentales de la inversión que pueda tener un impacto importante en la rentabilidad esperada de la inversión, deberá comunicarlo sin demora al promotor del proyecto, que deberá completarla o corregirla sin dilación. Si el promotor no cumpliera esta obligación sin demora, el proveedor suspenderá la oferta hasta la subsanación por parte del promotor, por un plazo máximo de 30 días naturales. Asimismo, deberá informar inmediatamente a los inversores que hubieran formulado una oferta de inversión o manifestado interés en la oferta de las irregularidades detectadas, de las medidas que hubiera tomado y que tomará el proveedor de servicios de financiación participativa y de la opción de retirar su oferta de inversión o su manifestación de interés en la oferta de financiación participativa. Es decir que, detectada la omisión o inexactitud, los inversores podrán retirar su oferta. Finalmente, si pasados los 30 días naturales señalados, el promotor no hubiera subsanado la ficha de datos fundamentales de la inversión, se anulará la oferta de financiación participativa (art. 23.12 Reglamento 2020/1503).

Por otro lado, el proveedor deberá solicitar al promotor que le notifique cualquier cambio de información, de modo que pueda mantener actualizada la ficha en todo momento y durante todo el periodo que dure la oferta de financiación participativa. Realizado cualquier cambio sustancial de la información contenida en la ficha, y siempre que le haya sido notificado por el promotor, el proveedor habrá de comunicárselo inmediatamente a los inversores que hubieran formulado una oferta de inversión o hubieran manifestado interés en la oferta de financiación participativa (art. 23.8 Reglamento 2020/1503).

Por lo que respecta a la responsabilidad por el contenido de la ficha, el art. 23.9 Reglamento 2020/1503 estipula que esta deberá recaer, como mínimo, en el 
promotor del proyecto o en sus órganos de administración, dirección o supervisión. Estas personas responsables deberán identificarse claramente en la ficha. A mayores, los Estados miembros velarán porque sus disposiciones legales, reglamentarias y administrativas sobre responsabilidad civil se apliquen a las personas físicas y jurídicas responsables de la información proporcionada en una ficha de datos fundamentales de la inversión, incluida su posible traducción, como mínimo, cuando: (i) la información sea engañosa o inexacta, o (ii) la ficha omita datos fundamentales necesarios para ayudar a los inversores a la hora de considerar la financiación del proyecto de financiación participativa (art. 23.10 Reglamento 2020/1503).

\section{Ficha de datos fundamentales de la inversión a nivel de plataforma}

Si el proveedor de servicios de financiación participativa prestase el servicio de gestión individualizada de carteras de préstamos, deberá elaborar una ficha de datos fundamentales de la inversión a nivel de plataforma, adicional a la ficha de datos fundamentales de la inversión realizada por el promotor, que deberá poner a disposición de los potenciales inversores (art. 24.1 Reglamento 2020/1503) ${ }^{9}$.

El contenido de esta ficha deberá ser imparcial, claro y no engañoso, y deberá cumplir con los mismos requisitos formales que la ficha de datos fundamentales de la inversión (art. 24.3 Reglamento 2020/1503).

La ficha de datos fundamentales de la inversión a nivel de plataforma deberá contener (art. 24.1 Reglamento 2020/1503):

a) La información requerida en las partes H (tarifas, información y vías de recurso) e I (información sobre el servicio de gestión individualizada de carteras de préstamos que presten los proveedores de servicios de financiación participativa) de la ficha de datos fundamentales de la inversión;

b) La información sobre las personas físicas o jurídicas responsables de la información proporcionada en la ficha de datos fundamentales de la inversión; así como

c) Una declaración de responsabilidad con el siguiente contenido: "El proveedor de servicios de financiación participativa declara que, hasta donde alcanza su conocimiento, no se ha omitido ningún dato y la información no es sustancialmente engañosa ni inexacta. El proveedor de servicios de financiación participativa es responsable de la preparación de esta ficha de datos fundamentales de la inversión".

El proveedor deberá mantener actualizada en todo momento esta ficha y deberá, igualmente, informar inmediatamente a los inversores de cualquier cambio sustancial

\footnotetext{
${ }^{9}$ Cuando se facilite a los inversores potenciales una ficha de datos fundamentales de la inversión a nivel de plataforma elaborada de conformidad con lo dispuesto en el presente artículo, se considerará que los proveedores de servicios de financiación participativa cumplen la obligación de elaborar un documento de datos fundamentales de conformidad con el Reglamento (UE) n.o 1286/2014 (PRIIPs), art. 24.8 Reglamento 2020/1503.
} 
de la información en la ficha de datos fundamentales de la inversión (art. 24.2 Reglamento 2020/1503).

Si el proveedor detectase alguna omisión, inexactitud o error en la ficha, que pueda tener un impacto importante en la rentabilidad esperada de la gestión individualizada de carteras de préstamos, deberá subsanarlo (art. 24.7 Reglamento 2020/1503). Nótese que en estos casos no se prevé plazo para subsanar, ni obligación de comunicación a los inversores, ni facultad de estos de retirarse.

En relación con la responsabilidad por su contenido, en estos casos, recaerá como mínimo en el proveedor de servicios de financiación participativa, debiendo constar claramente en la ficha las personas responsables (art. 24.4 Reglamento 2020/1503). Nuevamente, los Estados miembros velarán por que sus disposiciones legales, reglamentarias y administrativas sobre responsabilidad civil se apliquen a las personas físicas y jurídicas responsables de la información proporcionada en una ficha de datos fundamentales de la inversión a nivel de plataforma, incluida su posible traducción, en, como mínimo, cuando la información contenida sea engañosa o inexacta; o cuando la ficha omita datos fundamentales necesarios para ayudar a los inversores a la hora de considerar si invertir mediante una gestión individualizada de carteras de préstamos (art. 24.5 Reglamento 2020/1503).

\section{Prueba inicial de conocimientos y simulación de la capacidad de soportar pérdidas}

Recordemos que en MiFID II existen dos pruebas distintas de evaluación que debe efectuar el prestador del servicio de inversión al cliente, en virtud de que el servicio prestado sea de asesoramiento o gestión de carteras o no. En este sentido, si el servicio prestado fuera de asesoramiento o gestión de carteras, la empresa de servicios de inversión viene obligada a efectuar la evaluación de idoneidad, en la que habrá de consultar sobre los conocimientos y experiencia del cliente o posible cliente en el ámbito de inversión correspondiente al tipo concreto de producto o servicio, su situación financiera, incluida su capacidad para soportar pérdidas, y sus objetivos de inversión incluida su tolerancia al riesgo, con el fin de que la empresa pueda recomendarle los servicios de inversión e instrumentos financieros que sean idóneos para él (art. 25.2 MiFID II). Ahora bien, si el servicio prestado no fuera de asesoramiento ni gestión de carteras, tan solo debería efectuar la evaluación de conveniencia, esto es, consultar sobre sus conocimientos y experiencia en el ámbito de inversión correspondiente al tipo concreto de producto o servicio ofrecido o solicitado, de modo que la empresa de servicios de inversión pueda evaluar si el servicio o producto de inversión previsto es conveniente para el cliente.

En relación con ello, el art. 21.2 Reglamento 2020/1503 exige que los proveedores de servicios de financiación participativa realicen una prueba de idoneidad a los inversores no experimentados ${ }^{10}$, antes de darles pleno acceso para invertir en

\footnotetext{
${ }^{10}$ Como señala TAPIA HERMIDA, la obligación es del proveedor-intermediario: "la protección del inversor en el ámbito de los servicios de financiación participativa comparte la regla general del ámbito de los servicios financieros que exige al intermediario - en este caso al proveedor- «conoce a tu cliente» para
} 
proyectos de financiación participativa de su plataforma de financiación participativa (art. 21.1 Reglamento 2020/1503), y deberá ser revisada cada dos años (art. 21.3 Reglamento 2020/1503) ${ }^{11}$.

Así, la prueba que ha de realizarse, decimos, se asemeja más al test de idoneidad previsto en MiFID II ya que comporta la obligación de recabar información del cliente sobre su experiencia, los objetivos de inversión, la situación financiera y la comprensión básica de los riesgos que conlleva invertir en general e invertir en los tipos de inversión ofrecidos en la plataforma de financiación participativa. Como puede observarse, a diferencia del test de conveniencia, esta información no se limita a la experiencia y conocimientos del cliente, sino que se extiende a la situación financiera del potencial inversor y a sus objetivos de inversión, como sucede en la evaluación de idoneidad.

Además, el art. 21.1 Reglamento 2020/1503 detalla que la información sobre los conocimientos y experiencia del potencial inversor comprenderá (i) las inversiones anteriores en valores negociables o las adquisiciones pasadas de instrumentos admitidos con fines de financiación participativa o los préstamos del inversor no experimentado potencial, incluso en empresas en fase inicial o de expansión; y (ii) la comprensión por parte del inversor no experimentado potencial de los riesgos que conlleva la concesión de préstamos, o la inversión en valores negociables o la adquisición de instrumentos admitidos con fines de financiación participativa a través de una plataforma de financiación participativa, así como la experiencia profesional pertinente para las inversiones de financiación participativa.

Asimismo, en relación con la situación financiera del potencial inversor y su capacidad para soportar pérdidas, los proveedores deberán solicitar a los inversores no experimentados potenciales que simulen su capacidad de soportar pérdidas, calculadas como el $10 \%$ de su patrimonio neto, en función de: (i) sus ingresos regulares e ingresos totales, y si dichos ingresos se devengan de forma permanente o temporal; (ii) sus activos, incluidas las inversiones financieras y cualquier depósito en efectivo, pero excluidos los bienes inmobiliarios personales y de inversión y los fondos de pensiones; y (iii) los compromisos financieros, incluidos los periódicos, actuales o futuros (art. 21.5 Reglamento 2020/1503). Pese a que la redacción del precepto parezca indicar que la obligación de realizar estas simulaciones recae sobre los propios inversores, lo cierto es que serán los proveedores quienes deban efectuarlas toda vez que el apartado 6 del art. 25 del Reglamento 2020/1503 indica que "[I]os inversores no experimentados acusarán recibo de los resultados de la

\footnotetext{
darle la protección adecuada". TAPIA HERMIDA, A. J.: "Decálogo de la nueva regulación europea del crowfunding", Diario la Ley, 4/11/2020.

${ }^{11}$ Como apunta LISSOWSKA "obliga al prestador del servicio de crowdfunding a obtener información del cliente, pero únicamente al comenzar el uso de la plataforma por el cliente ( $y$, más adelante, cada dos años), y sin que sea posible que la plataforma inhabilite el acceso del cliente por considerar que la oferta es inadecuada para su perfil. No se prevé, sin embargo, un test de idoneidad de ofertas específicas". LISSOWSKA, M.: "La regulación europea del crowdfunding", en CUENA CASAS, M. (Dir.) Aspectos legales de la financiación en masa o crowdfunding, Tirant lo Blanch, 2020, p. 114.
} 
simulación a que se refiere el apartado 5", lo que exige que les haya sido entregada por el proveedor.

Con todo, la finalidad de la evaluación de idoneidad configurada en MiFID II y el ordenado en el Reglamento 2020/1503 difiere sustancialmente en uno y otro caso. Mientras que el test de idoneidad MiFID II tiene como finalidad que la empresa de servicios de inversión pueda recomendar al cliente los servicios de inversión e instrumentos financieros que sean idóneos para él, esto es, que mejor se ajusten a su nivel de tolerancia al riesgo y su capacidad para soportar pérdidas (art. 25.2 MiFID II); la finalidad del test de idoneidad del Reglamento 2020/1503 es dar a los inversores no experimentados potenciales pleno acceso para invertir en proyectos de financiación participativa de la plataforma de financiación participativa del proveedor, e identificar cuáles de sus proyectos son adecuados para el potencial inversor. Es decir, en el Reglamento 2020/1503 no existe obligación de asesoramiento ni de efectuar recomendaciones, sino solo de identificar qué proyectos se adecuan a los conocimientos, experiencia y situación financiera del potencial inversor.

Por otro lado, en caso de que la evaluación de idoneidad sea negativa o no pueda realizarse porque el inversor no facilite la información necesaria para ello, el proveedor solo vendrá obligado a informar al inversor no experimentado potencial de que los servicios ofrecidos en sus plataformas de financiación participativa pueden ser inadecuados para ellos y les advertirán del riesgo. Esta advertencia deberá indicar claramente el riesgo de pérdida de la totalidad del dinero invertido. Además, los inversores potenciales no experimentados deberán reconocer expresamente que han recibido y comprendido la advertencia emitida por el proveedor de servicios de financiación participativa ${ }^{12}$ (art. 21.4 Reglamento 2020/1503). A mayor abundamiento, el art. 21.6 Reglamento 2020/1503 indica directamente que "[n]o se impedirá a los inversores no experimentados potenciales ni a los inversores no experimentados invertir en proyectos de financiación participativa", cabría añadir, "incluso cuando el proyecto no sea adecuado para él".

Como puede apreciarse, la falta de superación de la evaluación de idoneidad se asemeja a la consecuencia de la falta de superación del test de conveniencia MiFID II (art. 25.3.II MiFID II). Ello es debido a la diferente finalidad del test de idoneidad del Reglamento 2020/1503 respecto a la finalidad del test de idoneidad MiFID II expuesta.

\section{Advertencia específica para inversiones "elevadas" de inversores no experimentados}

De conformidad con el art. 21.7 Reglamento 2020/1503, cada vez que el inversor no experimentado potencial o un inversor no experimentado pueda aceptar una oferta de financiación participativa que suponga una inversión superior a $1000 €$ o al $5 \%$ de su patrimonio neto (el importe que resulte más elevado), y antes de que la acepte, el proveedor de servicios de financiación participativa garantizará que dicho inversor: (i) reciba una advertencia de riesgo; (ii) manifieste su consentimiento expreso al

12 Este reconocimiento expreso no está previsto en MiFID II para el caso de que la evaluación de conveniencia fuera negativa. 
proveedor de servicios de financiación participativa, y (iii) demuestre al proveedor de servicios de financiación participativa que entiende la inversión y sus riesgos. Esta demostración de comprensión quedará satisfecha si de la evaluación de idoneidad se infería tal comprensión.

Como señala PALÁ LAGUNA "[a] diferencia del derecho español en el que se establecen límites a la inversión por parte de los inversores minoristas (artículo 82 de la Ley 5/2015), el Reglamento europeo únicamente requiere para inversiones superiores a 1.000 euros 0 al $5 \%$ del patrimonio neto del inversor no acreditado eligiendo el que sea más elevado de los dos- especiales obligaciones de información por el proveedor de servicios de financiación (comunicación al inversor "una advertencia de riesgo" y requerimiento de su expreso consentimiento)"13. En efecto, el art. 82 LFFE impide a los inversores no acreditados invertir más de $3000 €$ en un mismo proyecto de una plataforma; así como invertir más de $10000 €$ en doce meses en distintos proyectos de una misma plataforma.

De este modo, no se establecen límites a las inversiones efectuadas por los inversores no experimentados, incluso cuando el considerando 46 sostenga que "[h]abida cuenta de los riesgos que entrañan los proyectos de financiación participativa, los inversores no experimentados deberían evitar exponerse de forma excesiva a los mismos. Existe un riesgo considerable de perder partes importantes de las cantidades inicialmente invertidas o incluso de perderlas en su totalidad. Por lo tanto, conviene fijar las cantidades máximas que los inversores no experimentados pueden invertir en cada proyecto, sin salvaguardias adicionales". Probablemente esta ausencia de límites sea consecuencia del atajamiento de las asimetrías de la información a través de las fichas de datos fundamentales de la inversión pues, como resalta CUENA CASAS "[e]I establecimiento de límites de inversión es un remedio cuando no se puede luchar contra las asimetrías de información"14.

\section{Información pública sobre la tasa de impago}

Los proveedores de servicios de financiación participativa que presten servicios de financiación participativa consistentes en la facilitación de la concesión de préstamos deberán publicar la tasa de impago, en un lugar destacado su sitio web, de conformidad con las siguientes reglas (art. 20.1 y 2 Reglamento 2020/1503).

a) Deberán publicar anualmente las tasas de impago de los proyectos de financiación participativa ofrecidos durante los treinta y seis meses anteriores, como mínimo; y

b) Deberán publicar una declaración de resultados dentro de los cuatro meses posteriores al final de cada ejercicio contable, en la que incluirán, según proceda: (i) la tasa de impago prevista y la efectiva de todos los préstamos

\footnotetext{
13 PALÁ LAGUNA, R.: "Nuevo régimen de los proveedores europeos de servicios de financiación participativa para empresas: el Reglamento (UE) 2020/1503, de 7 de octubre", GA-P, disponible en: https://www.ga-p.com/publicaciones/nuevo-regimen-de-los-proveedores-europeos-de-servicios-de-

financiacion-participativa-para-empresas-el-reglamento-ue-2020-1503-de-7-de-octubre/ (última consulta: 5/12/2020).

${ }^{14}$ CUENA CASAS, M.: op. cit., p. 482.
} 
que hubiera facilitado, por categoría de riesgo de conformidad con el marco de gestión de riesgos; (ii) un resumen de las hipótesis utilizadas para determinar las tasas de impago previstas; y (iii) el rendimiento real obtenido, si hubiera ofrecido una tasa objetivo en relación con la gestión individualizada de carteras de préstamos.

\section{Período de reflexión de inversores no expertos}

El proveedor de servicios de financiación participativa deberá establecer un período de reflexión precontractual, de 4 días naturales desde la oferta de inversión o expresión de interés del inversor no experimentado potencial, durante el cual el inversor no experimentado potencial podrá revocar en todo momento su oferta o expresión de interés, sin necesidad de justificar su decisión y sin incurrir en una sanción (art. 22.2 y 3 Reglamento 2020/1503). En consecuencia, se exige que los proveedores lleven un registro de inversión y de las expresiones de interés que reciban (ahora bien, de inversores experimentados y no experimentados), así como del momento en que se reciban (art. 22.4 Reglamento 2020/1503). La configuración de este derecho como periodo de reflexión y no de desistimiento comporta la prohibición, como señala el considerando 47 , de que los proveedores reciban ninguna suma del inversor ni se transfiera al promotor del proyecto antes de terminar el período de reflexión.

En este sentido, el proveedor de servicios de financiación participativa deberá facilitar información precisa, clara y oportuna a los inversores no experimentados potenciales sobre el período de reflexión y sus modalidades. Esta información se deberá ofrecer antes que el inversor no experimentado pueda comunicar su oferta o manifestar su interés, en cuyo caso deberá de que (i) la oferta de inversión o la manifestación de interés está sujeta a un período de reflexión; (ii) la duración del período de reflexión; y (iii) las modalidades para revocar una oferta de inversión o una manifestación de interés. También deberá informar de ello inmediatamente después de recibir la oferta de inversión o manifestación de interés al inversor no experimentado, a través de la plataforma de financiación participativa, indicando que ha comenzado el período de reflexión (art. 22.6 Reglamento 2020/1503).

Sin embargo, en caso de gestión individualizada de carteras de préstamos, el periodo de reflexión o desistimiento solo se aplicará al mandato de inversión inicial otorgado por el inversor no experimentado y no a las inversiones en préstamos específicos realizadas en el marco de dicho mandato (art. 22.7 Reglamento 2020/1503).

A pesar del derecho de reflexión del inversor no experimentado, las condiciones de la oferta de financiación participativa seguirán siendo vinculantes para el promotor del proyecto desde el momento en que la oferta de financiación participativa figure en la plataforma de financiación participativa, y hasta la fecha que acaezca antes de las siguientes: (i) la fecha de expiración de la oferta de financiación participativa anunciada por el proveedor en la oferta; o (ii) la fecha en que se alcance el objetivo de financiación o, en el caso de un intervalo de financiación, cuando se alcance el objetivo de financiación máxima (art. 22.1 Reglamento 2020/1503).

\section{Tablón de anuncios}


El art. 25.1 Reglamento 2020/1503 reconoce la facultad de los proveedores de crear un tablón de anuncios en el que sus clientes puedan anunciar su interés en la compraventa de préstamos, valores negociables o instrumentos admitidos para la financiación participativa que inicialmente se ofertaron en sus plataformas de financiación participativa. Si el proveedor propusiera un precio de referencia para la compraventa, deberá informar de que no es vinculante y justificar su determinación, así como hacer públicos los elementos de su metodología de cálculo (art. 25.5 Reglamento 2020/1503).

Ahora bien, este tablón de anuncios no podrá utilizarse para casar posiciones ni ejecutar órdenes por medio de los métodos o procedimientos de funcionamiento interno del proveedor de servicios de financiación participativa (art. 25.2 Reglamento 2020/1503).

Para que los proveedores puedan autorizar estos anuncios de interés, deberán cumplir con los siguientes requisitos:

a) Deberán informar a sus clientes sobre la naturaleza del tablón de anuncios y de que no es un mecanismo para casar posiciones;

b) Deberán exigir a los clientes que anuncien la venta de un préstamo, un valor o un instrumento, que pongan a disposición una ficha de datos fundamentales de la inversión;

c) Informarán a los clientes que tengan la intención de comprar préstamos anunciados en el tablón de anuncios sobre el rendimiento de los préstamos facilitados por el proveedor de servicios de financiación participativa; y

d) Deberán asegurarse de que los clientes que anuncien su interés en comprar un préstamo, un valor o un instrumento, que merezcan la consideración de inversores no experimentados, reciban la información a que se refiere el artículo 19, apartado 2 (ausencia de garantías de la inversión), y reciban la advertencia de riesgo a que se refiere el artículo 21, apartado 4 (posibilidad de pérdida de toda la inversión).

Si el proveedor prestara el servicio de custodia de activos, exigirá a los inversores que anuncien su interés en la compraventa de préstamos, valores negociables o instrumentos admitidos para la financiación participativa, que notifiquen todo cambio de titularidad a efectos de verificación de la titularidad y registro (art. 25.4 Reglamento 2020/1503).

\section{Conclusiones}

No puede negarse que el inversor no experimentado resulta más protegido en la regulación del Reglamento 2020/1503 que el inversor no acreditado en la LFFE. La medida estrella de protección a los inversores no acreditados en la LFFE no constituía más que un atajo normativo que denotaba una falta de interés (o capacidad) por abordar eficazmente la protección del pequeño inversor. 
Por el contrario, el Reglamento 2020/1503 sí afronta los sesgos conductuales del inversor y la asimetría informativa. Las fichas de datos fundamentales de la inversión, siguiendo la estela del Reglamento PRIIPs, permitirán que los inversores cuenten con la información precisa, claramente expuesta y fácilmente abordable dada su limitada extensión. Asimismo, resulta plausible la evaluación de los conocimientos, experiencia y situación financiera de los potenciales inversores no experimentados, así como la obligación de efectuar advertencias específicas cuando se dispongan a efectuar inversiones que puedan sobrepasar su capacidad de soportar pérdidas y la posibilidad de salida cuando la ficha del promotor adoleciera de omisiones o inexactitudes. También resulta positiva la regulación de las normas de conducta y de evitación de conflictos de interés, es especial, la obligación de proveedores de actuar en el mejor interés de sus clientes y la prohibición de percibir comisiones por orientar las órdenes de los inversores.

Con todo, el Reglamento 2020/1503 no ofrece el nivel de protección al inversor no experimentado que habría sido deseable. Muestra de ello es la regulación de la evaluación de los conocimientos y capacidad para soportar pérdidas, cuya superación o evaluación positiva no es necesaria para permitir la inversión; de hecho, ni siquiera refiere a operaciones u ofertas concretas, sino que tan solo constituye un requisito de acceso a la plataforma (con independencia, reiteramos, de su resultado). A mayor abundamiento, el Reglamento se muestra excesivamente centrado en la estipulación de disclaimers destinados a crear puertos seguros a los proveedores para blindarlos frente a eventuales reclamaciones.

\section{Bibliografía}

CAMACHO CLAVIJO, S.: "El crowdfunding: régimen jurídico de la financiación participativa en la Ley $5 / 2015$ de fomento de la financiación empresarial", Revista CESCO de Derecho de Consumo, no 17/2016, pp. 85-115.

CASASOLA DÍAZ, J. Ma.: "Las plataformas de financiación participativa: concepto, régimen y referencia especial a la protección del inversor consumidor", eXtoikos, no. 19, 2017, pp. 13-17.

CUENA CASAS, M.: "La protección del inversor en el crowdfunding lucrativo", en CUENA CASAS, M. (Dir.) Aspectos legales de la financiación en masa o crowdfunding, Tirant lo Blanch, 2020.

FLORES SEGURA, M.: "La tipología de inversores en las operaciones de financiación participativa o «crowdfunding»", Revista de Derecho Bancario y Bursátil, no 150, 2018, pp. 89-110.

LISSOWSKA, M.: "La regulación europea del crowdfunding", en CUENA CASAS, M. (Dir.) Aspectos legales de la financiación en masa o crowdfunding, Tirant lo Blanch, 2020.

PALÁ LAGUNA, R.: "Nuevo régimen de los proveedores europeos de servicios de financiación participativa para empresas: el Reglamento (UE) 2020/1503, de 7 de octubre", GA-P, disponible en: https://www.ga-p.com/publicaciones/nuevo-regimende-los-proveedores-europeos-de-servicios-de-financiacion-participativa-para- 
empresas-el-reglamento-ue-2020-1503-de-7-de-octubre/ (última consulta: 5/12/2020).

TAPIA HERMIDA, A. J.: La nueva regulación europea del crowfunding (4): El Reglamento (UE) 2020/1503, de 7 de octubre de 2020, sobre los proveedores europeos de servicios de financiación participativa para empresas", disponible en: http://ajtapia.com/2020/10/la-nueva-regulacion-europea-del-crowfunding-4-elreglamento-ue-2020-1503-de-7-de-octubre-de-2020-sobre-los-proveedoreseuropeos-de-servicios-de-financiacion-participativa-para-empresas/ (última consulta: 5/12/2020).

TAPIA HERMIDA, A. J.: "Decálogo de la nueva regulación europea del crowfunding", Diario la Ley, 4/11/2020.

ZUNZUNEGUI, F.: "Régimen jurídico de las plataformas de financiación participativa (crowdfunding)", Revista de Derecho del Mercado Financiero, junio 2015, pp. 1-32. 